\title{
Reduced graphene oxides with engineered defects enable efficient electrochemical reduction of dinitrogen to ammonia in wide $\mathrm{pH}$ range
}

\author{
Mingli Zhang ${ }^{\dagger}$, Changhyeok $\mathrm{Choi}^{\ddagger}$, Rupeng $\mathrm{Huo}^{\dagger}$, Song Hong ${ }^{\dagger}$, Chao Yan ${ }^{\bar{\top}}$, Suying Xư ${ }^{\top}$, Alex W. Robertson ${ }^{\mp}$, Jieshan

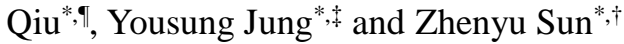 \\ † State Key Laboratory of Organic-Inorganic Composites, College of Chemical Engineering, Beijing University of Chemical \\ Technology, Beijing 100029, P. R. China. E-mail: sunzy@mail.buct.edu.cn \\ ‡ Graduate School of EEWS, Korea Advanced Institute of Science and Technology (KAIST) Daejeon 34141, Republic of Korea. E- \\ mail: ysjn@kaist.ac.kr \\ ' School of Material Science \& Engineering, Jiangsu University of Science and Technology, Zhenjiang 212003, P. R. China \\ ¥ Department of Materials, University of Oxford, Oxford OX1 3PH, United Kingdom \\ ^ State Key Laboratory of Chemical Resource Engineering, College of Chemical Engineering, Beijing University of Chemical \\ Technology, Beijing, 100029, P. R. China
}

\begin{tabular}{|c|c|}
\hline A R T I C L E I N F O & A B S T R A C T \\
\hline $\begin{array}{l}\text { Keywords: } \\
\text { Nitrogen reduction } \\
\text { Defect } \\
\text { Metal-free catalysis } \\
\text { Electrocatalyst }\end{array}$ & $\begin{array}{l}\text { Electrochemical nitrogen fixation under mild conditions is highly demanded yet } \\
\text { remains a grand challenge. Herein we report metal-free electrocatalysis of aqueous } \\
\mathrm{N}_{2} \text { reduction to produce } \mathrm{NH}_{3} \text { over defective reduced graphene oxide (DrGO) with } \\
\text { tuned defects. The defect sites, consisting of unsaturated carbon [single vacancy } \\
(\mathrm{SV} \text { ), double vacancy (DV), and -COOH], in DrGO were examined, and showed } \\
\text { an improved } \mathrm{NH}_{3} \text { selectivity due to the strong binding of } \mathrm{N}_{2} \text { instead of } \mathrm{H} \text {. In addition } \\
\text { to improved selectivity, the calculated free energies for } \mathrm{N}_{2} \text { reduction reaction at } \\
\text { DrGO-COOH and DrGO-DV sites suggest that the thermodynamic ovepotentials } \\
\text { of these metal-free catalysts are at least comparable to the most efficient transition } \\
\text { metal-based catalysts reported thus far. Our nonmetallic and dopant-free catalysts } \\
\text { can convert } \mathrm{N}_{2} \text { to } \mathrm{NH}_{3} \text { at a faradaic efficiency of up to } 22.0 \% \text { at }-0.116 \mathrm{~V} \text { (versus } \\
\text { the reversible hydrogen electrode vs. RHE) in } 0.1 \mathrm{M} \mathrm{HCl} \mathrm{and} 10.8 \% \text { at }-0.166 \mathrm{~V} \\
\text { (vs. RHE) in } 0.1 \mathrm{M} \mathrm{KOH} \text {, surpassing most earlier reported catalysts. An } \mathrm{NH}_{3} \\
\text { formation rate exceeding } 7.3 \mu \mathrm{g} \cdot \mathrm{h}^{-1} \mathrm{mg}^{-1} \text { was achieved at low overpotentials in both } \\
\text { acidic and alkaline environments, comparable to the values shown by metal } \\
\text { electrocatalysts under similar conditions. }\end{array}$ \\
\hline
\end{tabular}

\section{Introduction}

Electrochemical $\mathrm{N}_{2}$ reduction (ENR) using solar- or windgenerated electricity is a simple and green $\mathrm{NH}_{3}$ production method. ${ }^{1}$ It can proceed through reaction of $\mathrm{N}_{2}$ with $\mathrm{H}_{2} \mathrm{O}\left(\mathrm{N}_{2}+\right.$ $6 \mathrm{H}_{2} \mathrm{O}+6 \mathrm{e}^{-} \rightleftharpoons 2 \mathrm{NH}_{3}+6 \mathrm{OH}^{-}$), without feeding in $\mathrm{H}_{2}$, as the required $\mathrm{H}_{2}$ is generated in situ by water electrolysis. This can be achieved under mild conditions. Associative nitrogen adsorption at active sites is likely the rate-limiting step, rather than the dissociative adsorption that is key to the Haber-Bosch process. Two steps are supposed to be crucial to the $\mathrm{N}_{2}$ reduction reaction (NRR): the reductive adsorption of $\mathrm{N}_{2}$ to form $\mathrm{N}_{2} \mathrm{H}^{*}$ (* indicates an active site on the catalyst) without needing to first break the triple bond in $\mathrm{N}_{2}$, and the reductive desorption of $\mathrm{NH}_{2}{ }^{*}$ to form $\mathrm{NH}_{3}{ }^{2}$ An ideal catalyst needs to selectively stabilize $\mathrm{N}_{2} \mathrm{H}^{*}$ but destabilize $\mathrm{NH}_{2} *$. There are currently two major challenges associated with ENR: (1) A large overpotential and (2) a low faradaic efficiency (FE) toward $\mathrm{NH}_{3}$ due to the competing hydrogen evolution reaction (HER), especially in protic solvents. ${ }^{3}$ Transition metals having a combination of unoccupied (forming $\sigma$ bonds) and occupied (forming $\pi$ bond symmetry) d-orbitals can accept an electron from, and backdonate to, $\mathrm{N}_{2} \cdot{ }^{4}$ A number of transtion metalbased catalysts, such as $\mathrm{Au},{ }^{5} \mathrm{Pt} / \mathrm{C},{ }^{6} \mathrm{Ru},{ }^{7,}{ }^{8} \mathrm{Mo},{ }^{9} \mathrm{Rh},{ }^{10} \mathrm{Pd} / \mathrm{C},{ }^{2}$ $\mathrm{Ag} / \mathrm{Au},{ }^{11} \mathrm{Bi}_{4} \mathrm{~V}_{2} \mathrm{O}_{11} / \mathrm{CeO}_{2},{ }^{12} \mathrm{WO}_{3},{ }^{13}$ and $\mathrm{Fe} /$ carbon nanotubes $(\mathrm{CNTs})^{14}$ have been reported to be effective in ENR. Only a limited types of p-block compounds and main-group elements can bind and activate $\mathrm{N}_{2} \cdot{ }^{4,15-17}$ However, these systems reported to date suffer from slow reaction kinetics, low $\mathrm{N}_{2}$ adsorption and reduction activity. A bottle-neck trade-off issue needs to be tackled; i.e., high FE is usually obtained only at the expense of low $\mathrm{NH}_{3}$ production rate. It is therefore of significance to develop naturally abundant, low cost, selective, and energyefficient electrocatalysts that enable both high $\mathrm{NH}_{3}$ selectivity and $\mathrm{NH}_{3}$ synthesis rate at low overpotentials. 
Recently, nonmetallic nanocarbon materials have shown promise for a range of electrochemical reactions. ${ }^{18}$ In addition to tuning of morphology, doping with single or multiple heteroatoms $\mathrm{s}^{3,19,20}$ is usually employed to profoundly modify the electronic structure of the carbon matrix, affording efficient electrocatalysis. Modification by introducing defects (such as point defects, one-dimensional defects, and edge defects) provides an even simpler and dopant-free strategy to yield effective electrocatalysts, yet this area is still in its early stages. ${ }^{21}$ Despite recent advances in this direction, the metalfree activation and reduction of $\mathrm{N}_{2}$ remains elusive. Here, we show for the first time that reduced graphene oxide with tuned defects (DrGO) is capable of catalyzing aqueous NRR to $\mathrm{NH}_{3}$ at room temperature and atmospheric pressure. Manipulation of the defect level of DrGO permits tuning of its catalytic properties in NRR. Note that no nitrogen is present in our DrGO samples, avoiding confounding effects from the element on electrolytic ammonia synthesis. Importantly, such a metal-free catalyst can deliver a high $\mathrm{NH}_{3}$ yield rate of about $8.5 \mu \mathrm{g} \cdot \mathrm{h}^{-1}$ $\mathrm{mg}^{-1}$ at $-0.266 \mathrm{~V}$ (vs. the reversible hydrogen electrode, RHE) higher than that of precious $\mathrm{Ru} / \mathrm{C}, \mathrm{Pd} / \mathrm{C}, \mathrm{Pt} / \mathrm{C}$, and tetrahexahedral Au nanorods. ${ }^{5}$ A very high $\mathrm{N}_{2}$ to $\mathrm{NH}_{3} \mathrm{FE}$ of approximately $22.0 \%$ was also achieved at a low applied potential of $-0.116 \mathrm{~V}$, even outperforming earlier reported metal-based catalysts. All potentials reported in this work are with regard to the RHE scale unless stated otherwise.

\section{Results and discussion}

(a)

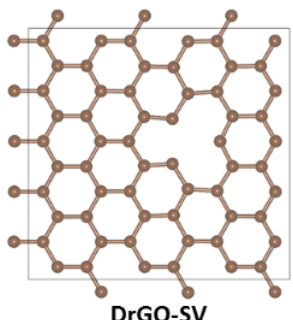

(b)

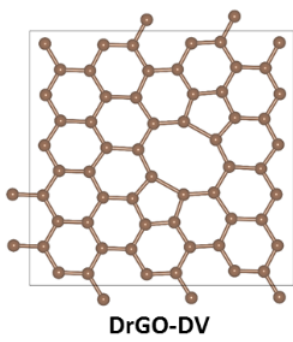

(c)

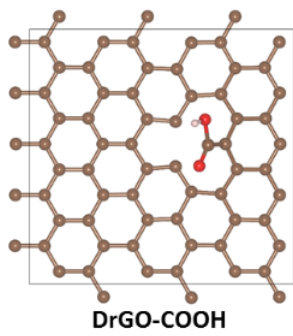

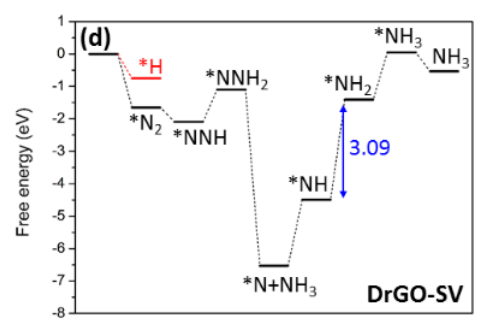
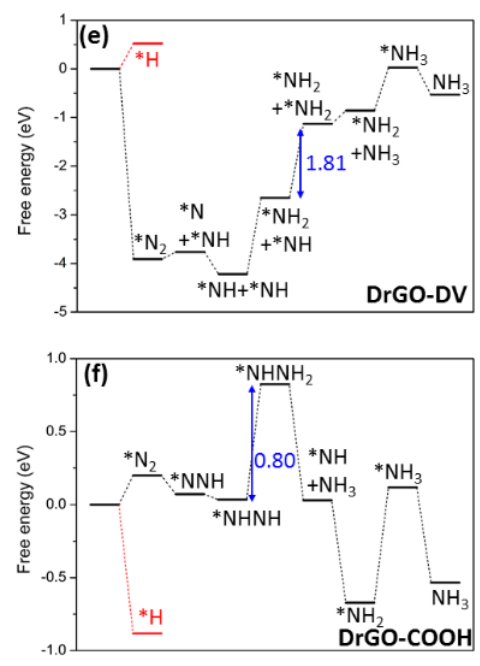

Figure. 1 Simulations of Electrochemical Nitrogen Reduction on Different Atomic Sites. Different atomic configurations for the calculations (a, b, and c). The free energy diagrams for NRR on DrGO-SV (in d), DrGO-DV (in e), and DrGO-COOH (in f). Black and red lines indicate free energies for NRR and HER, respectively. The $\Delta \mathrm{GpDs}(\mathrm{eV})$ is denoted in blue in the figure. First desorbed $\mathrm{NH}_{3}$ is omitted for clarity.

To elucidate the role of defect sites in DrGO for $\mathrm{N}_{2}$ reduction, we first performed density functional theory (DFT) calculations on various defect structures in graphene. We considered oxygen-containing functional groups (epoxide, $\mathrm{OH},-\mathrm{CO},-\mathrm{COOH}$ ), and structural defects in the basal plane (55-77, 555-777, 555-6-777, single vacancy (SV), and double vacancy (DV)) and on edge sites (armchair edge (AC), AC-677, zigzag edge (ZZ) and ZZ-57). ${ }^{22}$ Among them, we found that the defect sites consisting of unsaturated carbon (SV, DV, and $\mathrm{COOH}$ ) can only activate $\mathrm{N}_{2}$, and for all other defect sites, either $\mathrm{N}_{2}$ and ${ }^{*} \mathrm{NNH}$ are not adsorbed or the free energies for $\mathrm{N}_{2}$ adsorption and $* \mathrm{NNH}$ formation are too high $(>1.5 \mathrm{eV})$. Thus, we focused here on SV, DV, -COOH embedded graphene models denoted as DrGO-SV, DrGO-DV, and DrGO-COOH, respectively. The free energy diagrams and reaction intermediates for NRR and HER are shown in Fig. 1 and Supporting Information (Figs. S1-S6).

The free energy changes of $\mathrm{N}_{2}$ binding $\left(\Delta G\left({ }^{*} \mathrm{~N}_{2}\right)\right)$ for DrGO-SV and DrGO-DV are -1.65 and $-3.91 \mathrm{eV}$ respectively, indicating that carbon vacancy sites can bind $\mathrm{N}_{2}$ strongly (Fig. $1 \mathrm{~d}$ and e). The highly elongated $\mathrm{N}-\mathrm{N}$ bond lengths of adsorbed

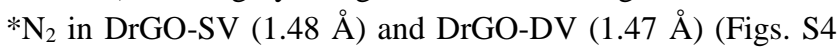
and S5) compared to that of unbounded $\mathrm{N}_{2}(1.12 \AA)$ suggest that $\mathrm{N}_{2}$ can be significantly activated at carbon vacancy sites. On DrGO-SV, ${ }^{*} \mathrm{~N}_{2}$ can be easily reduced to $* \mathrm{NNH}$ and produce the first $\mathrm{NH}_{3}\left(* \mathrm{~N}+\mathrm{NH}_{3}\right)$ with $0.99 \mathrm{eV}$ free energy reqirement $\left({ }^{*} \mathrm{NNH} \rightarrow{ }^{*} \mathrm{NNH}_{2}\right.$ ) (Fig. 1a). However, due to the high stability of * $\mathrm{N}$ (graphitic $\mathrm{N}$ ) and $* \mathrm{NH}$ reaction intermediates, a large free energy penalty is required to produce the second $\mathrm{NH}_{3}$ to close the catalytic cycle. The potential-determining step (PDS) is $* \mathrm{NH} \rightarrow{ }^{*} \mathrm{NH}_{2}$, and the associated free energy change at this $\operatorname{PDS}\left(\Delta G_{\mathrm{PDS}}\right)$ is $3.09 \mathrm{eV}$.

On the other hand, for DrGO-DV $* \mathrm{~N}_{2}$ can be highly stabilized by filling the carbon double vacancies (Fig. S5). Due to its much weakened and elongated $\mathrm{N}-\mathrm{N}$ bond in ${ }^{*} \mathrm{~N}_{2}$ and a stronger adsorption, it forms $* \mathrm{~N}+* \mathrm{NH}$ rather than $* \mathrm{NNH}$ after the first protonation (Fig. 1e). The PDS and $\Delta G_{\mathrm{PDS}}$ on DrGODV are $* \mathrm{NH} \rightarrow{ }^{*} \mathrm{NH}_{2}$ and $1.81 \mathrm{eV}$, respectively. Contrary to DrGO-SV and DrGO-DV, the $\Delta G\left({ }^{*} \mathrm{~N}_{2}\right)$ is endothermic on DrGO-COOH $(0.20 \mathrm{eV})$ (Fig. 1f), but the $\Delta G_{\mathrm{PDS}}$ for NRR on DrGO-COOH is $0.80 \mathrm{eV}$ for the protonation step ${ }^{*} \mathrm{NHNH} \rightarrow$ * $\mathrm{NHNH}_{2}$.

We also found an improved NRR selectivity of carbon defect sites in terms of binding energy of $* \mathrm{~N}_{2}$ and $* \mathrm{H}$. A previous theoretical study on NRR demonstrated that most metal surfaces favor the ${ }^{*} \mathrm{H}$ adsorption than the NRR reaction intermediates such as $* \mathrm{~N}$ and ${ }^{*} \mathrm{~N}_{2}$, indicating that most metal surfaces would be easily covered by $* \mathrm{H}$ in NRR experiments, blocking the active sites for $\mathrm{N}_{2}$ binding and subsequent NRR. ${ }^{23}$ In other words, favorable $* \mathrm{H}$ adsorption compared to ${ }^{*} \mathrm{~N}_{2}$ binding would decrease the NRR selectivity, in addition to catalyzing HER side reaction itself. ${ }^{24}$ These results suggest as a 
guideline to design efficient NRR catalysts that, in addition to lowering $\Delta \mathrm{G}_{\mathrm{PDS}}$, increased ${ }^{*} \mathrm{~N}_{2}$ binding relative to ${ }^{*} \mathrm{H}$ is also important to suppress $\mathrm{H}$ binding and increase NRR selectivity. The $\Delta G\left({ }^{*} \mathrm{~N}_{2}\right)$ of DrGO-SV $(-1.65 \mathrm{eV})$ and DrGO-DV (-3.91 $\mathrm{eV})$ are indeed much more negative than $\Delta G\left({ }^{*} \mathrm{H}\right)$ of DrGO-SV $(-0.75 \mathrm{eV})$ and DrGO-DV $(0.52 \mathrm{eV})$ at zero potential, suggesting a high $* \mathrm{~N}_{2} / * \mathrm{H}$ selectivity on DrGO-SV and DrGODV. Compared to DrGO-SV and DrGO-DV, DrGO-COOH shows a lower $* \mathrm{~N}_{2} / * \mathrm{H}$ selectivity (Fig. 1 ).
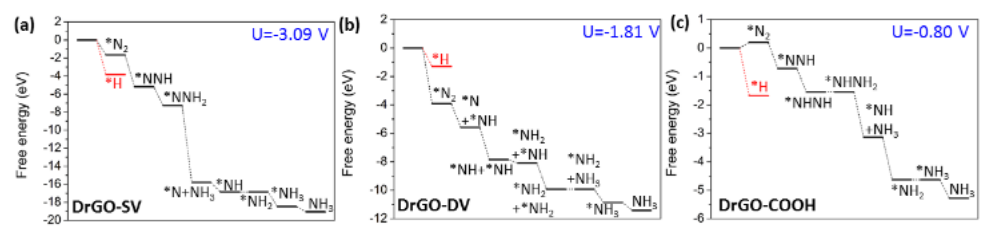

Figure 2. The free energy diagrams for NRR and $\mathrm{H}$ binding at limiting potential for NRR on (a) DrGO-SV, (b) DrGO-DV, and (c) DrGO-COOH.

We also considered NRR vs. HER at more realistic negative potentials that can initiate NRR (Fig. 2). Since the ${ }^{*} \mathrm{H}$ binding $\left(\mathrm{H}^{+}+\mathrm{e}^{-} \rightarrow{ }^{*} \mathrm{H}\right)$ is affected by the applied potential whereas a thermal $\mathrm{N}_{2}$ binding is not influenced by a potential, one would expect an increase in the ${ }^{*} \mathrm{H}$ binding at a negative potential that may result in a decrease in the $* \mathrm{~N}_{2} / * \mathrm{H}$ selectivity under experimental NRR conditions. Interestingly, however, the DrGO-DV still showed a more negative $\Delta \mathrm{G}\left({ }^{*} \mathrm{~N}_{2}\right)(-3.91 \mathrm{eV})$ than $\Delta \mathrm{G}\left({ }^{*} \mathrm{H}\right)(-1.29 \mathrm{eV})$ even at negative potentials (Fig. S2b), suggesting that $\mathrm{N}_{2}$ binding would be substantially less hindered by ${ }^{*} \mathrm{H}$ under the NRR experimental conditions for these materials sites.

\section{(a)}
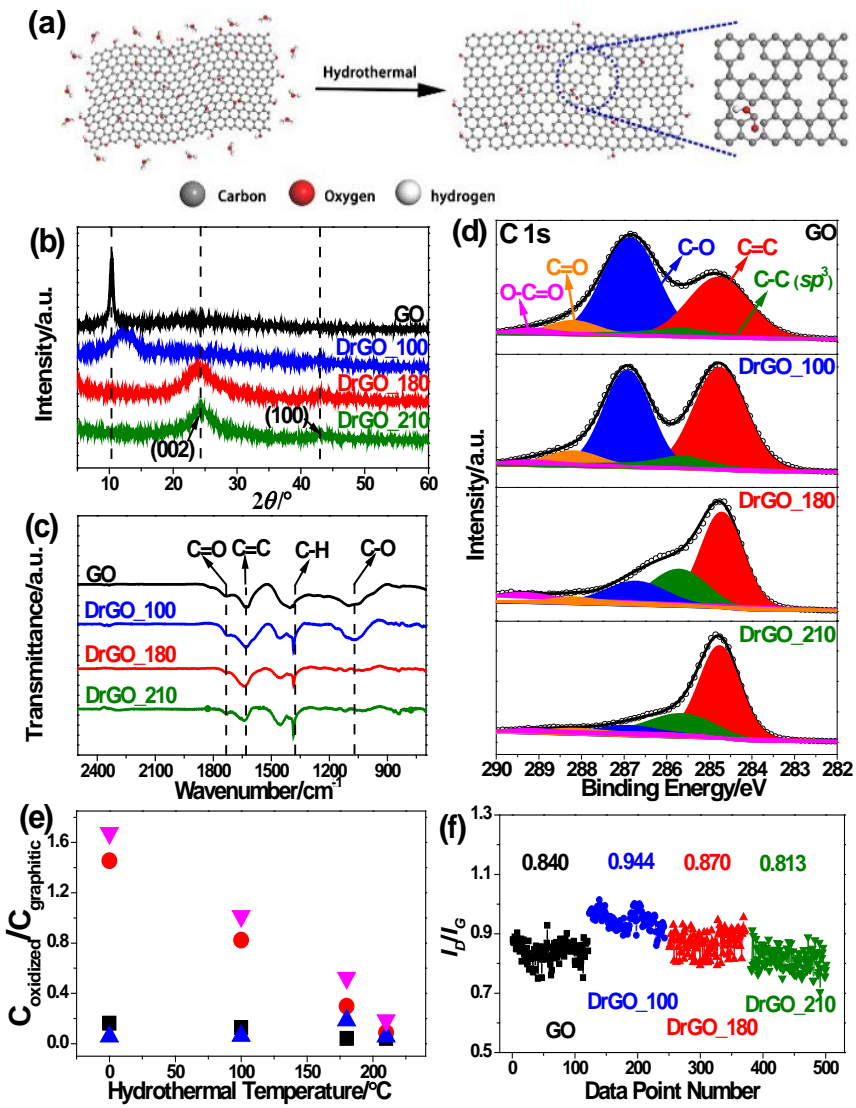

Figure 3. Schematic and Characterization of DrGO Catalysts. (a) Schematic illustration of the preparation of DrGO. (b) XRD patterns, (c) FTIR spectra, and (d) C 1s XPS spectra of GO and DrGO samples obtained at varying hydrothermal temperatures. (e) The molar ratios of $\mathrm{C}$ singly bound to oxygen $(\bullet)$, carbon doubly bound to oxygen $(\boldsymbol{\bullet})$, carbon bound to two oxygen atoms $(\boldsymbol{\Delta})$ and the sum of the three $C(\nabla)$ to graphitic $C$ as a function of hydrothermal T. (f) The D-to-G peak intensity ratios of GO and DrGO samples. In each case, 121 different spots were measured.

To validate the predication of the DFT calculations, we prepared DrGO samples with tailored defect levels by hydrothermal treatment of graphene oxide (GO) in an autoclave at 100,180 , and $210{ }^{\circ} \mathrm{C}$, which are referred to as DrGO_100, DrGO_180, and DrGO_210, respectively (Fig. 3a). During heating in water, GO can undergo disproportionation reactions, resulting in carbon vacancies in its basal plane. In contrast to harsh direct heating in air or oxygen plasma treatment that breaks the percolating network of graphitic domains, our method is milder with a good control over the progress of removal of $s p^{3}$ carbon and creation of the defective sites.

The X-ray diffraction (XRD) patterns of pristine GO and the resultant samples are given in Fig. 3b. Weakening of the typical GO peak at $\sim 10^{\circ}$ occurred with increasing hydrothermal temperature, which essentially disappeared at $T \geq 180{ }^{\circ} \mathrm{C}$. Meanwhile, the diffraction peaks at $\sim 26.5^{\circ}$ and $43.1^{\circ}$, respectively attributable to the (002) and (100) reflections of a graphitic hexagonal structure, appeared and became sharper with $T$. This strongly indicates that GO with highly oxidized domains was largely reduced after hydrothermal treatment. Fourier-transform infrared spectroscopy (FTIR) revealed that the peaks at around 1731 and $1076 \mathrm{~cm}^{-1}$, corresponding to the stretching vibrations of $\mathrm{C}=\mathrm{O}$ and $\mathrm{C}-\mathrm{O}$ groups, significantly weakened with increasing reaction temperature, suggesting the removal of oxygen functionalities during the heat treatment step (Fig. 3c). X-ray photoelectron spectroscopy (XPS) analysis was further employed to probe the surface oxygen species in the samples (Fig. S7). A pronounced C 1s peak at $286.8 \mathrm{eV}$, attributed to carbon singly bound to oxygen in phenols and ethers (i.e., C-O), ${ }^{18}$ was observed in both pristine GO and DrGO_100 (Fig. 3d). Carbon doubly bound to oxygen in ketones and quinones (i.e., $\mathrm{C}=\mathrm{O}$ ) at $288.2 \mathrm{eV}$ and carbon bound to two oxygen atoms in carboxyls, carboxylic anhydrides, and esters (i.e., -COO) at $289.2 \mathrm{eV}$ were identified as well. We further estimated the ratios of the various $\mathrm{O}$ species bound to $\mathrm{C}$ and graphitic $\mathrm{C}\left(s p^{2}\right)$ and their dependence on the hydrothermal treatment temperature, as shown in Fig. 3e. It shows that the original GO contains $58.8 \%$ oxidized C and $35.1 \%$ graphitic C. All the three ratios tended to decrease with hydrothermal temperature, likely due to the deoxygenation of GO. The graphitic carbon content increased up to $65.7 \%$ at $210{ }^{\circ} \mathrm{C}$ (12.2\% oxidized C). We also found that the $s p^{3} \mathrm{C}-\mathrm{C}$ peak became more pronounced with the increase of $T$, indicating the formation of more carbon vacancies after removal of oxygenated group defect sites. Deconvolution of the $\mathrm{O} 1 \mathrm{~s}$ spectra manifested three peaks at $530.85,532.3$, and $533.4 \mathrm{eV}$, suggesting the presence of various oxygen-containing 
functional groups with doubly and singly bound oxygen (Fig. S8a). The relative ratio of $\mathrm{O}$ singly or doubly bound to $\mathrm{C}$ follows a similar trend to the results obtained based on the $\mathrm{C} 1 \mathrm{~s}$ XPS spectra (Fig. S8b). The O content was found to decrease with increasing temperature, from $33.5 \%$ for GO to $13.4 \%$ for DrGO_210. The C/O ratio in the resultant DrGO_210 was 6.45, which is much higher as compared to GO with a $\mathrm{C} / \mathrm{O}$ ratio of 1.98. These observations suggest partial restoration of the graphitic domains after hydrothermal treatment, thus leading to improved electrical conductivity.

Raman spectroscopy allowed us to study the extent of the generated defects. The Raman spectra of GO and DrGO samples all showed an intense $\mathrm{G}$ band and a disorder-related $\mathrm{D}$ peak (Fig. S9). The defect level, as a function of hydrothermal temperature, was investigated in terms of the integrated Raman peak intensity $\left(A_{D} / A_{G}\right)$ and the average peak intensity of the $D$ band relative to the $\mathrm{G}$ band $\left(I_{\mathrm{D}} / I_{\mathrm{G}}\right)$ (Fig. S10). $A_{\mathrm{D}} / A_{\mathrm{G}}$ and $I_{\mathrm{D}} / I_{\mathrm{G}}$ increased with reaction temperature up to $100{ }^{\circ} \mathrm{C}$, beyond which both tended to decrease with temperature (Figs. $3 \mathrm{f}$ and S11a). The values of $A_{\mathrm{D}} / A_{\mathrm{G}}(\sim 0.94)$ and $I_{\mathrm{D}} / I_{\mathrm{G}}(\sim 0.81)$ for the DrGO_210 are both lower than those of pristine GO $\left(A_{\mathrm{D}} / A_{\mathrm{G}}\right.$ : $\sim 1.2 ; I_{\mathrm{D}} / I_{\mathrm{G}}: \sim 0.84$ ), which may be due to the rate of removal of oxygenated group defects being greater than the addition of carbon vacancy defects during the disproportionation reactions. The in-plane crystallite sizes $\left(L_{\mathrm{a}}\right)$ of GO and DrGO were estimated using the equation $560\left(A_{\mathrm{D}} / A_{\mathrm{G}}\right)^{-1} / E^{4}$, where $E$ is the laser energy $(2.33 \mathrm{eV})$. We found that $L_{\mathrm{a}}$ first dropped upon treatment at $100{ }^{\circ} \mathrm{C}$, but started to rise with $T$ (Fig. S11b). We further calculated the distance between defects $\left(L_{\mathrm{D}}\right)$ and the defect density $\left(n_{\mathrm{D}}\right)$ using the approximations of $L_{\mathrm{D}}{ }^{2}\left(\mathrm{~nm}^{2}\right)=$ $4300\left(I_{\mathrm{D}} / I_{\mathrm{G}}\right)^{-1} / E^{4}$ and $n_{\mathrm{D}}\left(\mathrm{cm}^{-2}\right)=10^{14} / \pi L_{\mathrm{D}}{ }^{2}$, respectively. ${ }^{18} L_{\mathrm{D}}$ showed a similar trend to $L_{\mathrm{a}}$ as a function of $T$ (Fig. S11c). Although a prominent increase in $n_{\mathrm{D}}$ was observed for the DrGO_100 $\left(n_{\mathrm{D}}=2.06 \times 10^{11} \pm 1.72 \times 10^{10} \mathrm{~cm}^{-2}\right)$ compared to pristine GO $\left(n_{\mathrm{D}}=1.83 \times 10^{11} \pm 4.20 \times 10^{10} \mathrm{~cm}^{-2}\right)$, the value fell gradually with further increase of $T$ reaching $1.77 \times 10^{11} \pm 1.18$ $\times 10^{10} \mathrm{~cm}^{-2}$ (Fig. S11d). Given that the area occupied by a carbon atom in graphite is $\left(3^{3 / 2} / 4\right) d^{2}$, where $d$ is the carboncarbon bond length $(0.1421 \mathrm{~nm})$, the unperturbed domain size of the DrGO_210 is correlated to about 10,330 carbon atoms, comparable to $\sim 9900$ carbon atoms observed for chemically derived graphene. ${ }^{25}$
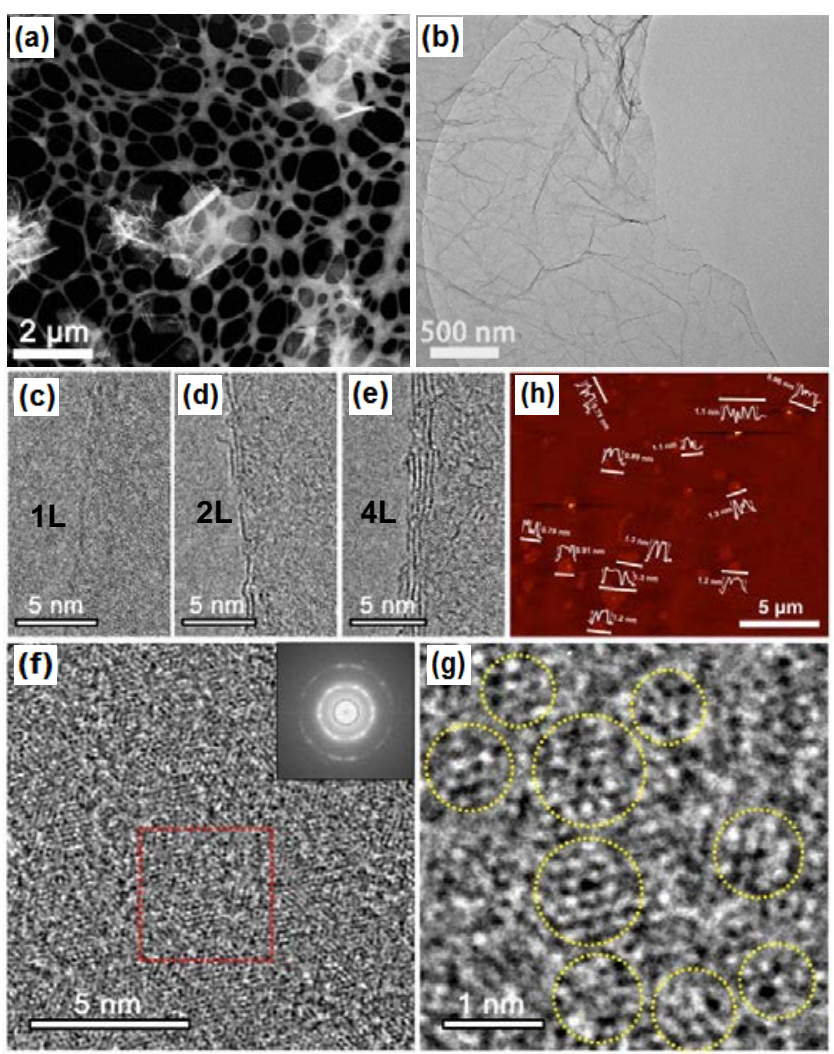

Figure 4. Morphology and Structure of DrGO_210 Catalyst. (a) HAADF-STEM and (b) TEM images of DrGO_210. HRTEM images of (c) single-layer, (d) two-layer, and (e) four-layer flakes. HRTEM images of (f) an individual layer and (g) selected region enclosed in $\mathrm{f}$. The inset in $\mathrm{f}$ shows the FFT of the image. Those crystalline areas in $g$ are marked by dotted circles, which contrast with those defect-rich regions. (h) AFM image with line-scan height profiles through different regions.

Scanning electron microscopy (SEM) (Fig. S12a and b) high-angle annular dark-field scanning transmission electron microscopy (HAADF-STEM) (Fig. 4a), and TEM images (Fig. 4b) show large quantities of graphene-like flakes regardless of hydrothermal treatment temperature. The sheet edges tend to scroll and fold slightly, similar to GO. Single-, double-, and four-layer flakes are clearly observed (Fig. 4c-e). The interlayer spacing was estimated to be about $0.35 \mathrm{~nm}$ (Fig. S12e and f), matching the value reported for graphene. HRTEM inspection (Fig. 4d and e), along with fast Fourier transform (FFT) (inset of Fig. 4d), provides solid evidences for well-crystallized DrGO_210. The FFT shows rings of intensity at $0.21 \mathrm{~nm}$ and $0.12 \mathrm{~nm}$, corresponding to the graphene (100) and (110) lattice spacings. Amorphous carbon and defects exist that contrast with those crystalline regions (as enclosed in dotted circles in Fig. 4e). Atomic force microscopy (AFM) observation indicates possible formation of pores or cracks on the surface of nanosheets, as reflected by variations of flake height during AFM line scans (Fig. 4f). 

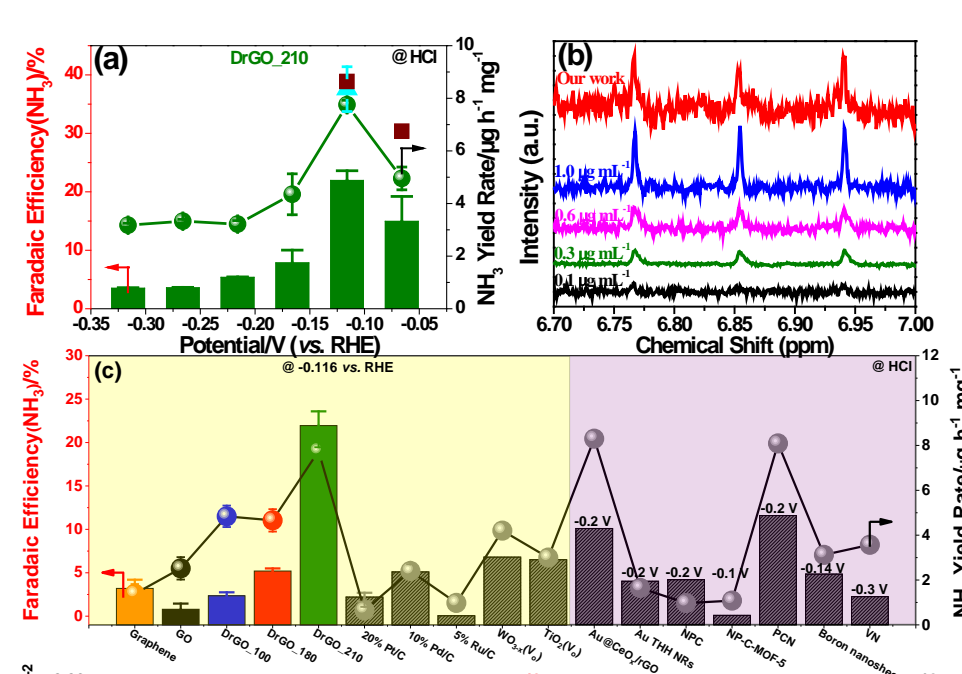

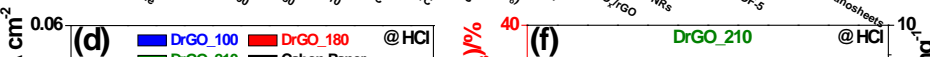
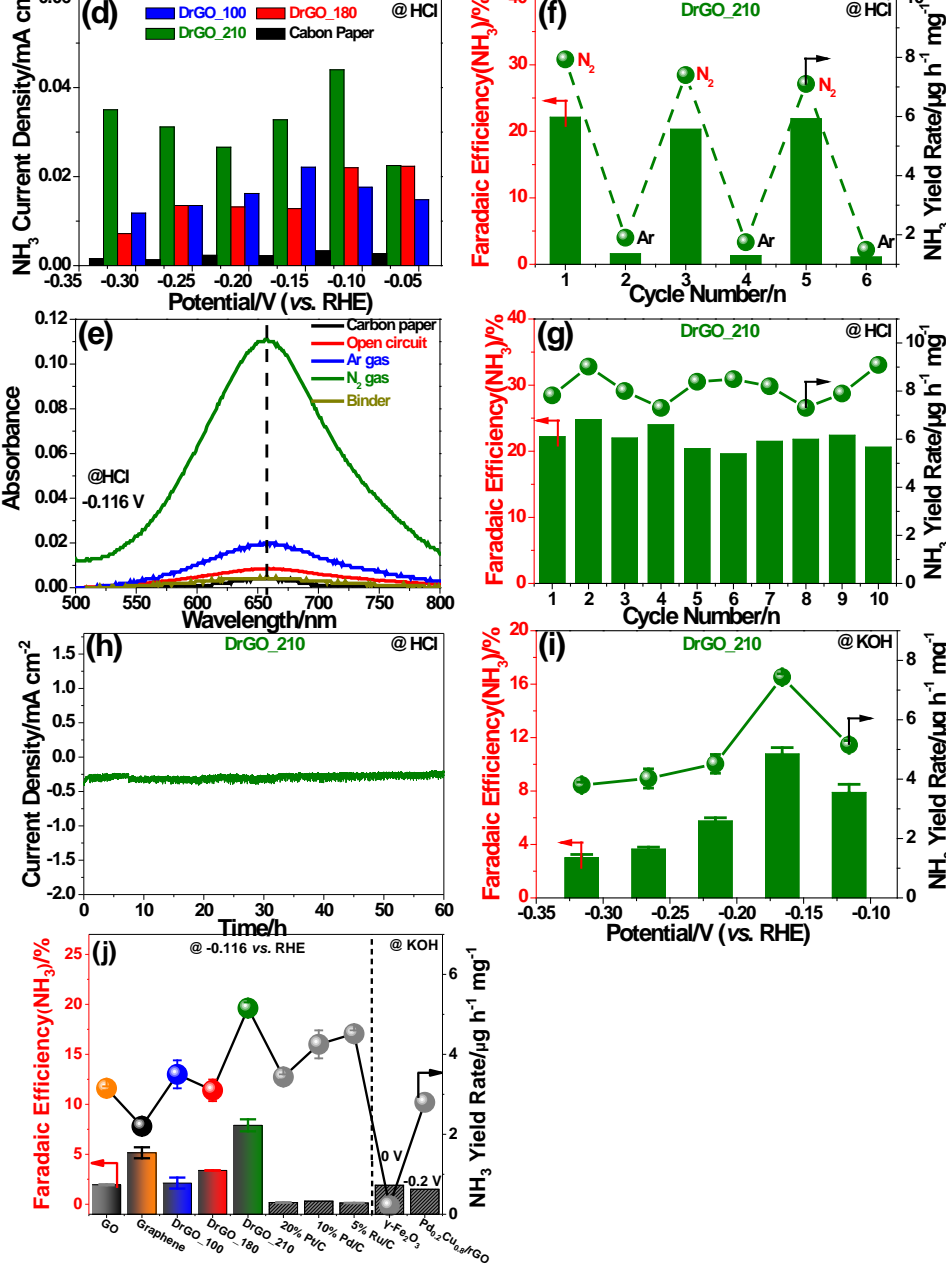

Figure 5. (a) The FEs and yield rates of $\mathrm{NH}_{3}$ over DrGO_210 at various potentials. The $\mathrm{NH}_{3}$ yield rates obtained by ion chromatography ( $\square$ ) and ${ }^{1} \mathrm{H}$ NMR ( $\triangle$ ) are provided as well. (b) ${ }^{1} \mathrm{H}$ NMR spectra for standard $\mathrm{NH}_{4}{ }^{+}$solutions with concentrations of $0.1,0.3,0.6,1.0 \mu \mathrm{g} \mathrm{mL}^{-1}$, and the electrolyte after electrolysis at $0.116 \mathrm{~V}$ in $\mathrm{N}_{2}$-saturated $0.1 \mathrm{M} \mathrm{HCl}$. (c) The FEs and yield rates of $\mathrm{NH}_{3}$ over graphene, GO, DrGO, commercial 20\% Pt/C, 10\% Pd/C, and $5 \% \mathrm{Ru} / \mathrm{C}$ electrodes at $-0.116 \mathrm{~V}$ in $\mathrm{N}_{2}$-saturated $0.1 \mathrm{M}$ aqueous $\mathrm{HCl}$. The results of $\mathrm{WO}_{3-\mathrm{x}}{ }^{13}$ and $\mathrm{TiO}_{2}{ }^{26}$ rich in oxygen vacancies, $\mathrm{Au} / \mathrm{TiO}_{2},{ }^{27} \mathrm{Au} @ \mathrm{CeO}_{\mathrm{x}} / \mathrm{rGO}^{28}$ and Au nanorods (Au THH NRs) ${ }^{5}$ reported for acidic NRR at applied potentials were also provided for comparison. The $\mathrm{NH}_{3}$ yield rates in all cases have been normalized by dividing corresponding electrode material mass. (d)
$\mathrm{NH}_{3}$ partical current densities over DrGOs and carbon paper at different potentials. (e) UV-vis absorption spectra of the electrolytes after electrolysis at $-0.266 \mathrm{~V}$ for the control experiments with Ar-saturated electrolyte (Ar gas), or without DrGO_210 catalyst (Carbon paper), or with only the background Nafion solution (Binder), or at an open circuit (Open circuit). (f) $\mathrm{NH}_{3}$ FEs and yield rates for DrGO_210 with alternated cycles between $\mathrm{Ar}$ - and $\mathrm{N}_{2}$-saturated $0.1 \mathrm{M} \mathrm{HCl}$ at $-0.116 \mathrm{~V}$. (g) The longterm durability test and (h) chronoamperometry measurements at §0.116 V over DrGO_210 electrode. The FEs and yield rates of $\mathrm{NH}_{3}$ sover (i) DrGO_210 at various potentials and (j) GO, graphene, DrGO, commercial $20 \% \mathrm{Pt} / \mathrm{C}, 10 \% \mathrm{Pd} / \mathrm{C}$, and $5 \% \mathrm{Ru} / \mathrm{C}$ electrodes 的 $-0.116 \mathrm{~V}$ in $\mathrm{N}_{2}$-saturated $0.1 \mathrm{M} \mathrm{KOH}$. The results of $\gamma-\mathrm{Fe}_{2} \mathrm{O}_{3}$ and

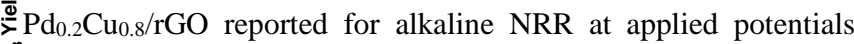
旁were also given for comparison.

The $\mathrm{N}_{2}$ reduction activity of all the catalysts was tested using a carbon paper working electrode in a gas-tight twocompartment electrochemical cell separated by a Nafion 117 membrane, operated at about $25{ }^{\circ} \mathrm{C}$ and atmospheric pressure (Fig. 5 and Figs. S13 and S14). Fig. S14a shows the linear sweep voltammetry (LSV) results of a DrGO sample in $0.1 \mathrm{M}$ aqueous $\mathrm{HCl}$ saturated with $\mathrm{Ar}$ or $\mathrm{N}_{2}$. We found that NRR takes place at potentials $>-0.066 \mathrm{~V}$ with an overpotential of $\leq$ $0.126 \mathrm{~V}$ (given the equilibrium thermodynamic potential for $\mathrm{N}_{2}$ reduction to $\mathrm{NH}_{3}$ is $0.06 \mathrm{~V}$ vs. NHE under our experimental conditions (298 K and $1 \mathrm{~atm}$ )) when using DrGO as a cathode catalyst (Figs. 5a and S14b, c and e). This onset potential is similar to that of metal catalysts but significantly more positive than the value attained on $\mathrm{N}$-doped porous carbon $(-0.38 \mathrm{~V}){ }^{20}$ Under the investigated reaction conditions, only $\mathrm{NH}_{4}{ }^{+}$was '? detected by the indophenol blue method. No $\mathrm{N}_{2} \mathrm{H}_{4}$ by-product was detectable by the Watt and Chrisp method ${ }^{29}$ within the detection limit of the method.

Electrolysis was also performed on DrGO_210 in Ar at $0.016 \mathrm{~V}$, which displayed undetectable $\mathrm{NH}_{3}$. This confirmed that $\mathrm{NH}_{3}$ is evolved from the $\mathrm{N}_{2}$ reduction. The $\mathrm{NH}_{3}$ yield rate and FE both increased initially ( -0.066 to $-0.116 \mathrm{~V})$ and then started to decrease with further increase of the applied potential (-0.116 to $-0.316 \mathrm{~V})$ (Fig. 5a), mostly due to occurrence of more predominant HER at more negative potentials. ${ }^{28}$ As shown in Fig. 5a and c, DrGO_210 displays an $\mathrm{NH}_{3}$ yield rate of $7.8 \mu \mathrm{g} \cdot \mathrm{h}$ ${ }^{1} \mathrm{mg}^{-1}\left(\sim 0.46 \mu \mathrm{mol} \mathrm{h}^{-1} \mathrm{~cm}^{-2}\right)$ at $-0.116 \mathrm{~V}$. This value is lower than $\sim 14.0 \mu \mathrm{g} \cdot \mathrm{h}^{-1} \mathrm{mg}^{-1}$ for $\mathrm{Au} / \mathrm{TiO}_{2}{ }^{27}$ but higher than $\sim 1.1 \mu \mathrm{g} \cdot \mathrm{h}^{-1} \mathrm{mg}$ ${ }^{1}$ for tetrahexahedral $\mathrm{Au}$ nanorods ${ }^{5}$ and $\sim 6.8 \mu \mathrm{g} \cdot \mathrm{h}^{-1} \mathrm{mg}^{-1}$ for $\mathrm{Au} / \mathrm{CeO}_{\mathrm{x}} / \mathrm{rGO}^{28}$ at similar potentials, and also those of reported $\mathrm{Ru}^{7}$ and Fe/CNT electrocatalysts (0.012-0.097 $\left.\mu \mathrm{mol} \mathrm{h}^{-1} \mathrm{~cm}^{-2}\right){ }^{14}$ The produced $\mathrm{NH}_{3}$ was also measured by ion chromatography and NMR spectroscopy. The $\mathrm{NH}_{3}$ yield rate was determined to be about 8.6 (Figs. 5a and S15a) and $8.3 \mu$ g $_{\mathrm{NH} 3} \mathrm{~h}^{-1}$ mgcat. $^{-1}$ (Figs. $5 \mathrm{a}$ and $\mathrm{b}$ and S15b) by ion chromatography and ${ }^{1} \mathrm{H}$ NMR measurements, respectively, comparable to the value of 7.8 $\mu_{\mathrm{NH} 3} \mathrm{~h}^{-1}$ mgcat. $^{-1}$ obtained by the indophenol blue method. Notably, the $\mathrm{NH}_{3}$ FE of DrGO_210 is as high as $22.0 \%$ even at a low potential of $-0.116 \mathrm{~V}$ (Fig. 5a and c), significantly surpassing liquid-exfoliated graphene $\left(\mathrm{NH}_{3} \mathrm{FE} \approx 3.2 \%\right.$ at -0.116 $\mathrm{V})$, original $\mathrm{GO}\left(\mathrm{NH}_{3} \mathrm{FE} \approx 0.8 \%\right.$ at $\left.-0.116 \mathrm{~V}\right)$, commercial $5 \mathrm{wt} \%$ 
$\mathrm{Ru} / \mathrm{C}\left(\mathrm{NH}_{3} \mathrm{FE} \approx 0.05 \%\right.$ at $\left.-0.116 \mathrm{~V}\right), \mathrm{Au} / \mathrm{TiO}_{2}\left(\mathrm{NH}_{3} \mathrm{FE} \approx 8.1 \%\right.$ at $-0.1 \mathrm{~V}),{ }^{27} \mathrm{Au} @ \mathrm{CeO}_{\mathrm{x}} / \mathrm{rGO}\left(\mathrm{NH}_{3} \mathrm{FE} \approx 10.1 \%\right.$ at $\left.-0.1 \mathrm{~V}\right),{ }^{28}$ tetrahexahedral $\mathrm{Au}$ nanorods $\left(\mathrm{NH}_{3} \mathrm{FE} \approx 4.0 \%\right.$ at $\left.-0.2 \mathrm{~V}\right){ }^{5}$ $\mathrm{Fe} / \mathrm{CNT}\left(\mathrm{NH}_{3} \mathrm{FE} \approx 0.15 \%\right.$ at $-1.0 \mathrm{~V}$ vs. Ag/AgCl), ${ }^{14}$ and $\mathrm{N}-$ doped porous carbon $\left(\mathrm{NH}_{3} \mathrm{FE} \approx 1.5 \%\right.$ at $\left.-0.9 \mathrm{~V}\right) .{ }^{20}$ As far as we are aware, this ranks as one of the highest $\mathrm{NH}_{3}$ FEs reported so far for aqueous NRR at ambient conditions. The $\mathrm{NH}_{3} \mathrm{FEs}$ were plotted against $I_{\mathrm{D}} / I_{\mathrm{G}}$ divided by oxygen content (Fig. S14f). As expected based on DFT calculations, the FE increased proportionally with the increase of $I_{\mathrm{D}} / I_{\mathrm{G}}$, representing the defect levels, and inverse of oxygen content associated with electrical conductivity The $\mathrm{NH}_{3}$ partial current density of DrGO_210 reached $0.046 \mathrm{~mA} \mathrm{~cm}^{-2}$ at $-0.116 \mathrm{~V}$ (Fig. $5 \mathrm{~d}$ ), comparable to the values reported for many metal catalysts. ${ }^{2,28}$ Experiments were also conducted at $-0.116 \mathrm{~V}$ under various $\mathrm{N}_{2}$ flow rates of 10 , 20,40 , and $60 \mathrm{~cm}^{3} \mathrm{~min}^{-1}$. Measurable effect of $\mathrm{N}_{2}$ flow rate was seen at flow rates $\leq 10 \mathrm{~mL} \mathrm{~min}^{-1}$, indicating that diffusion was the rate determining step. While no pronounced effect was observed in the $\mathrm{NH}_{3}$ yield rate within the experimental error at $\mathrm{N}_{2}$ flow rates above $20 \mathrm{~mL} \mathrm{~min}^{-1}$ (Fig. S14g).

To further verify the origin of $\mathrm{NH}_{3}$ generated, we performed multiple control experiments. As shown in Fig. 5e, very little or no $\mathrm{NH}_{3}$ was detected using the indophenol blue method in argon (99.999\% purity)-saturated electrolyte ( $\mathrm{Ar}$ gas), or with carbon paper electrode without DrGO (Carbon paper) (Fig. S14d), or with solely the background Nafion solution binder (Binder), or at an open circuit as a control (Open circuit). This strongly suggests that the $\mathrm{NH}_{3}$ was generated from electroreduction of dissolved $\mathrm{N}_{2}$ by DrGO catalyst.

The long-term performance of the catalyst was evaluated at a constant potential of $-0.116 \mathrm{~V}$ for cycles. Alternated electrolysis cycling test between $\mathrm{Ar}$ - and $\mathrm{N}_{2}$-saturated electrolytes indicated that the produced $\mathrm{NH}_{3}$ was evolved from the feed gas $\mathrm{N}_{2}$ and can be stable over 5 cycles (Fig. 5f). Although a drastic loss of activities in terms of both $\mathrm{NH}_{3}$ yield rate and FE occurred for DrGO_100, DrGO_180 as well as pristine $\mathrm{GO}$ (Fig. $\mathrm{S} 14 \mathrm{j}-\mathrm{l}$ ), the $\mathrm{NH}_{3}$ yield rate remained about 7.8 $\mu \mathrm{g} \cdot \mathrm{h}^{-1} \mathrm{mg}^{-1}$ for DrGO_210 after 10 cycles (10 h) (Fig. 5g), indicating good durability of the catalyst. Chronoamperometry measurements showed that the overall current density remained almost stable over $60 \mathrm{~h}$ (Fig. 5h). We performed XPS analyses on the electrode after the electrolysis. No evidence of $\mathrm{Ag}$ or $\mathrm{Pt}$ was observed on the electrode after the repeated experiments. This excluded the possibility that Ag leached out of the reference electrode (or Pt from the counter electrode) and got deposited on the working electrode during this chronoamperometry experiment, which would affect the electrochemical performance if occurred.

We also investigated the electrocatalytic fixation of $\mathrm{N}_{2}$ over DrGO samples under alkaline conditions (0.1 M KOH) (Fig. 5i and $\mathrm{j}$ and Fig. S16). As in the case of the acidic electrolyte, DrGO_210 performed better than the others. An $\mathrm{NH}_{3}$ yield rate of $7.4 \mu \mathrm{g} \cdot \mathrm{h}^{-1} \mathrm{mg}^{-1}$ at $-0.166 \mathrm{~V}$ was achieved in $0.1 \mathrm{M}$ aqueous $\mathrm{KOH}$ (Fig. 5i), which is higher than the value of $4.4 \mu \mathrm{g} \cdot \mathrm{h}^{-1} \mathrm{mg}^{-1}$ at $-0.166 \mathrm{~V}$ attained in $0.1 \mathrm{M} \mathrm{HCl}$. But the maximum $\mathrm{NH}_{3} \mathrm{FE}(10.8 \%$ at $-0.116 \mathrm{~V})$ is lower than the value of $22.0 \%$ at $-0.116 \mathrm{~V}$ obtained in $0.1 \mathrm{M} \mathrm{HCl}$.

We note some overestimation of thermodyamic overpotentials using the DFT calculated energy barriers for the present NRR compared to experimental overpotentials. This seemingly systematic overestimation has also been observed in recent theoretical studies of metal catalysts for NRR. For example, $\mathrm{Ru}$ and $\mathrm{Rh}$ surfaces, which are near at the top of the NRR volcano plot and hence supposedly efficient, were still estimated to have $>1 \mathrm{~V}$ theoretical overpotential, ${ }^{24}$ although the maximum $\mathrm{NH}_{3}$ yield rates of $\mathrm{Ru}$ cathodes and $\mathrm{Rh}$ nanosheet nanoassemblies were experimentally reported at $-1.02 \mathrm{~V}$ (vs. $\mathrm{Ag} / \mathrm{AgCl}$ ) and $-0.2 \mathrm{~V}$ (vs. RHE), respectively, corresponding to relatively smaller overpotentials $(<0.9 \mathrm{~V}) .^{5,7}$ Similarly, the $\mathrm{Au}(210)$ surface, the active sites for NRR on Au nanorods, also required $\sim 2 \mathrm{eV}$ of calculated free energy for $\mathrm{NRR},{ }^{7}$ but the maximum $\mathrm{NH}_{3}$ yield rate for $\mathrm{Au}$ nanorods was also shown at $0.2 \mathrm{~V}$ (vs. RHE), corresponding to an overpotential of 0.206 $\mathrm{V} .{ }^{10}$ In this regard, the $\Delta \mathrm{G}_{\mathrm{PDS}}$ calculated for the present DrGOCOOH (0.80 eV) and DrGO-DV (1.81 eV) show comparable or somewhat lower values than those of reported efficient transition metal catalysts described above.

\section{Conclusions}

In summary, we have shown here the possibility of realizing electrochemical synthesis of $\mathrm{NH}_{3}$ under mild conditions using reduced graphene oxides with a tuned quantity of defects. Such dopant-free nonmetallic catalysts can deliver significantly low overpotentials with a large faradaic efficiency for $\mathrm{N}_{2}$ to $\mathrm{NH}_{3}$ conversion ( $22.0 \%$ at $-0.116 \mathrm{~V}$ ), as well as high $\mathrm{NH}_{3}$ production rate $\left(7.8 \mu \mathrm{g} \cdot \mathrm{h}^{-1} \mathrm{mg}^{-1} \cdot\right.$ at $\left.-0.116 \mathrm{~V}\right)$ in acidic media. An $\mathrm{NH}_{3}$ faradaic efficiency of $10.8 \%$ and yield rate of $7.4 \mu \mathrm{g} \cdot \mathrm{h}^{-1} \mathrm{mg}^{-1}$ were also achieved at $-0.166 \mathrm{~V}$ in alkaline condition. The performances are comparable to, and even higher than, many earlier reported metal catalysts. DFT calculations revealed that carbon vacancy sites can bind $\mathrm{N}_{2}$ strongly but suppress the binding of $\mathrm{H}$, thereby improving the $\mathrm{NH}_{3}$ selectivity. Our results may guide rational catalyst design in metal-free electrocatalytic $\mathrm{N}_{2}$ reduction to $\mathrm{NH}_{3}$.

\section{Experimental}

\subsection{Reagents and materials}

All chemicals used in this work were of analytical grade and used as supplied. $\mathrm{K}_{2} \mathrm{~S}_{2} \mathrm{O}_{8}, \mathrm{KMnO}_{4}, \mathrm{P}_{2} \mathrm{O}_{5}, \mathrm{H}_{2} \mathrm{O}_{2}, \mathrm{NaOH}$, $\mathrm{C}_{5} \mathrm{FeN}_{6} \mathrm{Na}_{2} \mathrm{O}$, and para-(dimethylamino) benzaldehyde were purchased from Aladdin. $\mathrm{H}_{2} \mathrm{SO}_{4}$ (98\%) and $\mathrm{HCl}$ (37\%) were provided by Beijing Chemical Works. NaClO was purchased from Macklin. Nafion membranes were provided by Alfa Aesar. Graphite powder (product number 332461) was acquired from Sigma-Aldrich and used without further treatments. Ultrapure water $(18.2 \mathrm{megohm} \cdot \mathrm{cm})$ was obtained by using the Milli-Q Synthesis System. Nitrogen gas (99.999\% purity) and argon gas (99.999\% purity) were both provided by Beijing Haipu Gas Company. Ltd. 


\subsection{Preparation of defective reduced graphene oxide (DrGO)}

$20 \mathrm{mg}$ of graphene oxide powder was mixed with $4 \mathrm{~mL}$ of deionized water. The resulting dispersion was subjected to ultrasonication bath (KQ5200DE, $40 \mathrm{kHz}$ ) at certain temperature for $0.5 \mathrm{~h}$. The obtained brown dispersion was sealed in a $50-\mathrm{mL}$ Teflon-lined autoclave and maintained at different temperatures for different hours. Then the autoclave was naturally cooled to room temperature and the as-prepared DrGOs were taken out and washed with deionized water and ethanol three times, and then dried at $45^{\circ} \mathrm{C}$ overnight.

\subsection{Electrochemical measurements}

Typically, about $1.2 \mathrm{mg}$ of catalysts were dispersed in 240 $\mu \mathrm{L}$ of isopropanol aqueous solution (IPA-to- $\mathrm{H}_{2} \mathrm{O}$ volume ratio of $1: 1$ ) to form a homogeneous ink by sonicating for $1 \mathrm{~h}$. Such dispersion was then loaded onto a carbon paper electrode with an area of $1 \times 1 \mathrm{~cm}^{2}$ and dried under ambient conditions. Finally, $5 \mu \mathrm{L}$ of a Nafion solution ( $1 \mathrm{wt} \%$ ) was dropped on the carbon paper.

Controlled potential electrolysis of $\mathrm{N}_{2}$ was performed in an H-shape electrochemical cell with a Nafion 117 membrane to separate the working and counter electrode compartments. Before NRR tests, the Nafion membrane was pretreated by heating in $5 \% \mathrm{H}_{2} \mathrm{O}_{2}$ aqueous solution at $80{ }^{\circ} \mathrm{C}$ for $1 \mathrm{~h}$ and subsequently in $0.5 \mathrm{M} \mathrm{H}_{2} \mathrm{SO}_{4}$ at $80{ }^{\circ} \mathrm{C}$ for another $1 \mathrm{~h}$. Toray Carbon fiber paper with a size of $1 \mathrm{~cm} \times 1 \mathrm{~cm}$ was employed as working electrode. Pt wire and $\mathrm{Ag} / \mathrm{AgCl}$ electrodes were used as counter electrode and reference electrode, respectively. The potentials were controlled by an electrochemical working station (CHI 760E, Shanghai CH Instruments Co., China). All potentials in this study were measured against the $\mathrm{Ag} / \mathrm{AgCl}$ reference electrode (in $3 \mathrm{M}$ aqueous $\mathrm{KCl}$ corresponding to an $E_{\mathrm{Ag} / \mathrm{AgCl}}^{\circ}=0.205 \mathrm{~V}$ ) and converted to the RHE reference scale by

$E($ vs. RHE $)=E($ vs. Ag/AgCl $)+0.205+0.059 \times p H \quad$ (Eq. 1)

Electrocatalytic fixation of $\mathrm{N}_{2}$ was carried out at room temperature (about $25{ }^{\circ} \mathrm{C}$ ) and atmospheric pressure $\left(\mathrm{N}_{2}+\right.$ $\left.6 \mathrm{H}_{2} \mathrm{O}+6 \mathrm{e}^{-} \rightleftharpoons 2 \mathrm{NH}_{3}+6 \mathrm{OH}^{-}\right) \cdot \mathrm{N}_{2}$ (99.999\%) was purged into the electrolyte for at least $30 \mathrm{~min}$ to remove residual air in the reservoir, then controlled potential electrolysis was conducted at each potential for 60 min with $\mathrm{N}_{2}$ flowing through the cell. During the electrolysis, the electrolyte was agitated with a stirring bar at a stirring rate of about $350 \mathrm{rpm}$. $\mathrm{N}_{2}$ regulated by a mass flow controller (Sevenstar Instrument) at $20 \mathrm{~mL} \mathrm{~min}{ }^{-1}$ flowed through the cell. A flow rate of $20 \mathrm{~mL} \mathrm{~min}^{-1}$ was selected to ensure sufficient $\mathrm{N}_{2}$ transport to the surface while excluding interference from gas bubbles striking the surface. We performed DrGO catalyst in $\mathrm{N}_{2}$ experiments at least three times, each with a new electrode.

\subsection{Determination of ammonia}

Concentration of produced ammonia was spectrophotometrically determined by the indophenol blue method. ${ }^{30}$ In detail, $2 \mathrm{~mL}$ aliquot of the solution was removed from the electrochemical reaction vessel. Then, $2 \mathrm{~mL}$ of a $1 \mathrm{M}$ $\mathrm{NaOH}$ solution containing $5 \mathrm{wt} \%$ salicylic acid and $5 \mathrm{wt} \%$ sodium citrate was added, followed by addition of $1 \mathrm{~mL}$ of 0.05 $\mathrm{M} \mathrm{NaClO}$ and $0.2 \mathrm{~mL}$ of 1 wt $\% \mathrm{C}_{5} \mathrm{FeN}_{6} \mathrm{Na}_{2} \mathrm{O}$ (sodium nitroferricyanide) aqueous solution. After $2 \mathrm{~h}$ of incubation at room temperature, the absorption spectrum was measured using an ultraviolet-visible spectrophotometer. The formation of indophenol blue was determined based on the absorbance at a wavelength of $655 \mathrm{~nm}$. The concentration-absorbance curves were calibrated using standard ammonia chloride solutions, as shown in Fig. S13, which contained the same concentrations of $\mathrm{HCl}$ as used in the electrolysis experiments. The measurements with the background solutions (no $\mathrm{NH}_{3}$ ) were conducted for all experiments, and the background peak absorbance was subtracted from the measured peak absorbance of NRR experiments to estimate the $\mathrm{NH}_{3}$ concentrations and the faradaic efficiencies.

Ion chromatography was conducted on ICS-1100. Ion chromatograms of $\mathrm{NH}_{4} \mathrm{Cl}$ with different concentrations in 0.1 $\mathrm{M} \mathrm{HCl}$ were displayed in Fig. S15a and b. Based on the standard chromatograms, the quantity of ammonia produced from NRR at $-0.116 \mathrm{~V}$ (vs. RHE) was determined.

The concentration of ammonia was also quantified by NMR spectroscopy on a Bruker AV 600-MHz system (Fig. 5b and S15c). Specifically, $26 \mathrm{~mL}$ of aliquot extracted from the electrochemical cell after the NRR at $-0.12 \mathrm{~V}$ (vs. RHE) was first concentrated to approximately $1.5 \mathrm{~mL} \cdot{ }^{31} 500 \mu \mathrm{L}$ of the concentrated solution was mixed with $50 \mu \mathrm{L}$ of DMSO-d6 for ${ }^{1} \mathrm{H}$ NMR measurements.

\subsection{Determination of hydrazine}

The formation of hydrazine during electrolysis was examined by the method of Watt and Chrisp. ${ }^{29}$ A mixture of para-(dimethylamino) benzaldehyde (5.99 g), $\mathrm{HCl}$ (37\%, 30 $\mathrm{mL}$ ), and ethanol (300 mL) was used as a color reagent. To do calibration, a series of reference solutions were firstly prepared by pipetting suitable volumes of hydrazine hydrate-nitrogen 0.1 $\mathrm{M} \mathrm{HCl}$ solution in colorimetric tubes. Then, $5 \mathrm{~mL}$ of diluted $\mathrm{HCl}$ electrolyte ( $\mathrm{pH}$ 1) was prepared. Subsequently, $5 \mathrm{~mL}$ of the above prepared color reagent was mixed and stirred for $10 \mathrm{~min}$ at room temperature. Finally, the absorbance of the resulting solution was measured at $455 \mathrm{~nm}$, and the yields of hydrazine were estimated from a standard curve using $5 \mathrm{~mL}$ of residual electrolyte and $5 \mathrm{~mL}$ of color reagent.

\subsection{Calculation of $\mathrm{NH}_{3}$ faradaic efficiency (FE) and $\mathrm{NH}_{3}$ yield rate}

The FE was calculated from the charge consumed for $\mathrm{NH}_{3}$ generation and the total charge passed through the electrode:

$\mathrm{FE}=\left(3 F \times C_{\mathrm{NH} 3} \times V\right) / Q$

The yield rate of $\mathrm{NH}_{3}$ can be estimated using the following equation:

Yield rate $=\left(c_{\mathrm{NH} 3} \times V\right) /(t \times m)$

where $F$ is the faraday constant $\left(96485 \mathrm{C} \mathrm{mol}^{-1}\right), c_{\mathrm{NH} 3}$ is the measured $\mathrm{NH}_{3}$ concentration, $V$ is the volume of the electrolyte, $Q$ is the total charge passed through the electrode, $t$ is the 
electrolysis time $(1 \mathrm{~h})$, and $m$ is the metal mass or the total mass of the catalyst. The reported $\mathrm{NH}_{3}$ yield rate, FE, and corresponding error bars were obtained based on the measurements of at least three separately prepared samples under the same conditions.

\subsection{Computational details}

All calculations were performed using spin-polarized density-functional theory (DFT) methods implemented in the Vienna Ab initio Simulation Package (VASP) with projectoraugmented wave pseudopotential (PAW). ${ }^{32,} 33$ We used the RPBE exchange functional with the van der Waals (D3) correction and a cut-off energy was set to $500 \mathrm{eV} .^{34,35}$ The convergence criteria of total energy and forces were set to $10^{-5}$ $\mathrm{eV}$ and $0.05 \mathrm{eV} / \AA$, respectively.

A rectangular graphene supercell containing 60 carbon atoms was used to construct basal plane of graphene. To construct graphene edge structures, $(5 \times 2)$ armchair supercell and $(5 \times 4)$ zigzag supercell were used. (3x3x1) and $(1 \times 4 \times 1)$ Monkhorst-Pack mesh k-point were used for basal plane and edge site of graphene. More than $15 \AA$ of vacuum layers were included in all slab models.

The computational hydrogen electrode (CHE) model was used to estimate free energy profile for electrochemical reactions. ${ }^{36}$ In the $\mathrm{CHE}$ method, the chemical potential of proton and electron pair $\left(\mu\left(\mathrm{H}^{+}+\mathrm{e}^{-}\right)\right)$is estimated from the half of chemical potential of $\mathrm{H}_{2}$ gas $\left(0.5 \mu\left(\mathrm{H}_{2}\right)\right)$ and it can be shifted by -eU when the external potential $U$ is applied, i.e., $\mu\left(\mathrm{H}^{+}+\mathrm{e}^{-}\right)$ $=0.5 \mu\left(\mathrm{H}_{2}\right)-\mathrm{eU}$. Free energy corrections for adsorbates were calculated by using Atomic Simulation Environment (ASE) code. ${ }^{37}$ The free energy correction terms were calculated for all adsorbents on DrGO-COOH. Solvation effects were not included since solavation induced stabilization of adsorbates in the NRR is within $0.1 \mathrm{eV} .^{38}$

\section{Supporting Information}

Additional characterization and catalytic data can be found in the supporting information.

\section{Acknowledgment}

This work was supported by the State Key Laboratory of OrganicInorganic Composites (oic-201901001); the Beijing Natural Science Foundation (No. 2192039), the Beijing University of Chemical Technology (XK180301), the State Key Laboratory of Separation Membranes and Membrane Processes (Tianjin Polytechnic University, No. M2-201704). Y.J. acknowledges the support through the National Research Foundation of Korea from the Korean Government (2016M3D1A1021147, 2017R1A2B3010176).

\section{References}

[1] J.G. Chen, R.M. Crooks, L.C. Seefeldt, K.L. Bren, R.M. Bullock, M.Y. Darensbourg, P.L. Holland, B. Hoffman, M.J. Janik, A.K. Jones, M.G. Kanatzidis, P. King, K.M. Lancaster, S.V. Lymar, P. Pfromm, W.F. Schneider, R.R. Schrock, Science
360 (2018) eaar6611.

[2] J. Wang, L. Yu, L. Hu, G. Chen, H. Xin, X. Feng, Nat. Commun. 9 (2018) 1795.

[3] Y. Song, D. Johnson, R. Peng, D.K. Hensley, P.V. Bonnesen, L. Liang, J. Huang, F. Yang, F. Zhang, R. Qiao, Sci. Adv. 4 (2018) e1700336.

[4] C. Liu, Q. Li, C. Wu, J. Zhang, Y. Jin, D.R. MacFarlane, C. Sun, J. Am. Chem. Soc. 141 (2019) 2884-2888.

[5] D. Bao, Q. Zhang, F.L. Meng, H.X. Zhong, M.M. Shi, Y. Zhang, J.M. Yan, Q. Jiang, X.B. Zhang, Adv. Mater. 29 (2017) 1604799.

[6] T. Murakami, T. Nohira, T. Goto, Y.H. Ogata, Y. Ito, Electrochim. Acta 50 (2005) 5423-5426.

[7] V. Kordali, G. Kyriacou, C. Lambrou, Chem. Commun. (2000) 1673-1674.

[8] H. Tao, C. Choi, L.-X. Ding, Z. Jiang, Z. Han, M. Jia, Q. Fan, Y. Gao, H. Wang, A.W. Robertson, S. Hong, Y. Jung, S. Liu, Z. Sun, Chem 5 (2019) 204-214.

[9] D. Yang, T. Chen, Z. Wang, J. Mater. Chem. A 5 (2017) 18967-18971.

[10] H.M. Liu, S.H. Han, Y. Zhao, Y.Y. Zhu, X.L. Tian, J.H. Zeng, J.X. Jiang, B.Y. Xia, Y. Chen, J. Mater. Chem. A 6 (2018) 3211-3217.

[11] H.K. Lee, C. Koh, Y.H. Lee, C. Liu, I.Y. Phang, X. Han, C.K. Tsung, X.Y. Ling, Sci. Adv. 4 (2018) eaar3208.

[12] C. Lv, C. Yan, G. Chen, Y. Ding, J. Sun, Y. Zhou, G. Yu, Angew. Chem. Int. Ed. 57 (2018) 6073-6076.

[13] Z. Sun, R. Huo, C. Choi, S. Hong, T.-S. Wu, J. Qiu, C. Yan, Z. Han, Y. Liu, Y.-L. Soo, Y. Jung, Nano Energy 62 (2019) 869875.

[14] S. Chen, S. Perathoner, C. Ampelli, C. Mebrahtu, D. Su, G. Centi, Angew. Chem. Int. Ed. 56 (2017) 2699-2703.

[15] X.X. Zhang, Q. Liu, X.F. Shi, A.M. Asiri, Y.L. Luo, T.S. Li, X.P. Sun, J. Mater. Chem. A 6 (2018) 17303-17306.

[16] Q. Fan, C. Choi, C. Yan, Y. C. Liu, J. S. Qiu, S. Hong, Y. Jung, Z. Y. Sun, Chem. Commun. 55 (2019) 4246-4249.

[17] Y. Wang, M.M. Shi, D. Bao, F.L. Meng, Q. Zhang, Y.T. Zhou, K.H. Liu, Y. Zhang, J.Z. Wang, Z.W. Chen, D.P. Liu, Z. Jiang, M. Luo, L. Gu, Q.H. Zhang, X.Z. Cao, Y. Yao, M.H. Shao, Y. Zhang, X.B. Zhang, J.G.G. Chen, J.M. Yan, Q. Jiang, Angew. Chem. Int. Ed. 58 (2019) 9464-9469.

[18] H.C. Tao, C. Yan, A.W. Robertson, Y.N. Gao, J.J. Ding, Y.Q. Zhang, T. Ma, Z.Y. Sun, Chem. Commun. 53 (2017) 873876.

[19] S. Mukherjee, D.A. Cullen, S. Karakalos, K. Liu, H. Zhang, S. Zhao, H. Xu, K.L. More, G. Wang, G. Wu, Nano Energy 48 (2018) 217-226.

[20] Y. Liu, Y. Su, X. Quan, X. Fan, S. Chen, H. Yu, H. Zhao, Y. Zhang, J. Zhao, ACS Catal. 8 (2018) 1186-1191.

[21] L. Tao, Q. Wang, S. Dou, Z. Ma, J. Huo, S. Wang, L. Dai, Chem. Commun. 52 (2016) 2764-2767.

[22] F. Banhart, J. Kotakoski, A.V. Krasheninnikov, ACS Nano 5 (2011) 26-41.

[23] S. Egill, B. Thomas, G. Sigrídur, S. Felix, R. Jan, A.-P. Frank, V. Tejs, J. Hannes, N.r. Jens K, Phys. Chem. Chem. Phys. 14 (2011) 1235-1245.

[24] L. Zhang, S.M. Sharada, A.R. Singh, B.A. Rohr, Y. Su, L. Qiao, J.K. Nørskov, Phys. Chem. Chem. Phys. 20 (2018) 49824989.

[25] S. Eigler, M. Enzelberger-Heim, P.H. S. Grimm, W. Kroener, A. Geworski, C. Dotzer, M. Röckert, J. Xiao, C Papp, O. Lytken, H. P. Steinrück, P. Müller, A. Hirsch, Adv. Mater. 25 (2013) 3853-3857.

[26] Z. Han, C. Choi, S. Hong, T.-S. Wu, Y.-L. Soo, Y. Jung, J. Qiu, Z. Sun, Appl. Catal. B Environ. 257 (2019) 117896. 
[27] M.M. Shi, D. Bao, B.R. Wulan, Y.H. Li, Y.F. Zhang, J.M. Yan, Q. Jiang, Adv. Mater. 29 (2017) 1606550.

[28] S.J. Li, D. Bao, M.M. Shi, B.R. Wulan, J.M. Yan, Q. Jiang, Adv. Mater. 29 (2017) 1700001.

[29] G. Watt, J. Chrisp, Anal. Chem. 24 (1952) 2006-2008.

[30] Z. Di, Z. Linghong, R.E. Ruther, R.J. Hamers, Nature Materials 12 (2013) 836-841.

[31] L. Zhang, L.X. Ding, G.F. Chen, X. Yang, H. Wang, Angew. Chem. Int. Ed. 58 (2019) 2612-2616.

[32] P.E. Blochl, Physical review. B, Condensed matter 50 (1994) 17953-17979.

[33] G. Kresse, D. Joubert, D. Phys. Rev. B 59 (1999) 17581775.

[34] J.P. Perdew, K. Burke, M. Ernzerhof, Phys. Rev. Lett. 77 (1996) 3865-3868.

[35] B. Hammer, L.B. Hansen, J.K. Nørskov, Phys. Rev. B 59 (1999) 7413-7421.

[36] J.K. Nørskov, J. Rossmeisl, A. Logadottir, L. Lindqvist, J.R. Kitchin, T. Bligaard, H.J.K. Jonsson, J. Phys. Chem. B 108 (2004) 17886-17892.

[37] S.R. Bahn, K.W. Jacobsen, Comput. Sci. Eng. 4 (2002) 5666.

[38] J.H. Montoya, C. Tsai, A. Vojvodic, J.K. Nørskov, ChemSusChem 8 (2015) 2180-2186. 